\title{
CONTRATOS INTERNACIONAIS E AS CLÁUSULAS DE REVISÃO: REBUS SIC STANTIBUS, TEORIA DA IMPREVISÃO, CLÁUSULA DE HARDSHIP E A CONTRARIEDADE COM O PRINCÍPIO PACTA SUNT SERVANDA
}

\author{
Heloisa Camargo de Lacerda ${ }^{1}$
}

\section{RESUMO}

Os contratos internacionais diante da complexidade que os envolve e das inseguranças a que as partes contratantes estão submetidas, bem como, diante da autonomia da vontade em sentido amplo, apresentam cada vez mais cláusulas de renegociação e revisão, que proporcionam a manutenção do equilíbrio e da própria relação contratual - quando da ocorrência de circunstâncias que dificultam ou oneram excessivamente as prestações de uma das partes. Entretanto, a possibilidade de revisão contratual contrariaria o antigo princípio do pacta sunt servanda que determina a obrigatoriedade absoluta dos termos contratuais?

\section{ABSTRACT}

The international contracts ahead of the complexity that involves them and of the unreliability that the contracting parties are submitted, as well, as ahead of the autonomy of the will in ample direction, present each time more clauses of renegotiation and revision, that they provide protection of the balance and for the own contractual relation - when of the occurrence of circumstances that excessively make it difficult or burden the installments of one of the parts. However, the possibility of a contractual revision would oppose the old principle of pacta sunt servanda that determines the absolute obligatoriness of the contractual terms?

\footnotetext{
1 Acadêmica do $4^{\circ}$ ano do curso de Direito - Unicenp, membro do Núcleo de Direito Internacional da UFPR - contratos internacionais e arbitragem.
}

Revista Brasileira de Direito Internacional, Curitiba, v.2, n.2, jul./dez.2005 
PALAVRAS CHAVES: CONTRATOS INTERNACIONAIS - REVISÃO OBRIGATORIEDADE.

\section{KEY WORDS: INTERNATIONAL CONTRACTS - REVISION - OBLIGATORINESS.}

\section{INTRODUÇÃO}

Por ser o contrato um instrumento vital para a efetivação do comércio e, tendo em vista a liberdade contratual das partes para a escolha das cláusulas contratuais, bem como, o princípio orientador da contratação que determina a obrigatoriedade dos pactos, surge a problemática da contrariedade das cláusulas revisionistas - eleitas pelas partes - com relação ao princípio do pacta sunt servanda.

A relevância das cláusulas revisionistas na tentativa de manutenção dos contratos, especialmente os internacionais, e a importância da continuidade das relações contratuais diante do panorama econômico atual, em contraposição à necessidade de segurança jurídica trazida pelo princípio do pacta sunt servanda, fez acalorar o importante questionamento a respeito da contrariedade de tais institutos.

A resposta para esta problemática pode ocorrer basicamente de três formas. A primeira delas é pela afirmação de que o princípio do pacta sunt servanda é realmente contrário às teorias revisionistas. A segunda forma é pela afirmação de que apesar da contrariedade essa contraposição é necessária no cenário da contratação. E a terceira forma de responder à problemática seria pela afirmação de que os institutos, apesar de diversos entre si, em verdade não se contrariam ou se opõem, mas se complementam.

O reflexo prático decorrente das diferentes formas de resolução dessa problemática consiste, em possibilitar ou impossibilitar, a aplicação das teorias revisionistas. Se considerarmos a primeira opção de resposta, a aplicação das teorias de revisão, ficaria extremamente dificultada (já que contrariaria um 
princípio basilar do direito contratual), enquanto que, nas outras duas opções a aplicação se daria, respectivamente, de forma menos ou mais facilitada.

\section{CONCEITO DE CONTRATO}

O termo contrato pode ser conceituado como um ato jurídico, estabelecido pelo acordo de vontades de caráter tipicamente patrimonial ${ }^{2}$. $O$ contrato é o instrumento que faz mover o comércio, onde duas ou mais pessoas jurídicas ou físicas se unem em nome de um determinado fim econômico, constituindo obrigações, transferindo propriedades, constituindo demais direitos reais ou de serviços.

\section{A AUTONOMIA DA VONTADE}

Intimamente ligadas à noção de contrato temos a noção de autonomia da vontade e do princípio do pacta sunt servanda. A autonomia da vontade em seu sentido amplo determina que, as partes são livres para contratar conforme melhor lhes parecer, escolhendo seus instrumentos e cláusulas contratuais e que, sua manifestação de vontade, desde que livre de vícios, deve ser respeitada.

Em sentido estrito temos a autonomia da vontade para a escolha da lei aplicável ao contrato. Pode se dizer que o jurista francês do século XVI, Charles Dumoulin, foi o principal responsável pelo desenvolvimento do princípio da autonomia da vontade em sentido estrito ${ }^{3}$.

Apesar de amplamente aceito no cenário internacional, o princípio da autonomia da vontade em sentido estrito, foi bastante limitado pelo legislador nacional, que estabelece os elementos de conexão a serem utilizados na definição da lei contratual e, exclui a possibilidade de escolha da lei pelas partes ${ }^{4}$.

\footnotetext{
${ }^{2}$ PEREIRA, Caio Mário da Silva. Instituições de direito civil. 10ª ed. São Paulo: Forense, 1987.

3 ARAÚJO, Nádia de. Direito internacional privado: teoria e prática brasileira. 2 ed. Rio de Janeiro: Renovar, 2004. p. 324.

${ }^{4}$ ARAÚJO, Nádia de. Direito internacional privado: teoria e prática brasileira. 2 ed. Rio de Janeiro: Renovar, 2004. p. 329-330.
}

Revista Brasileira de Direito Internacional, Curitiba, v.2, n.2, jul./dez.2005 
A exceção a tal limitação ocorre em sede arbitral, onde a Lei Brasileira de Arbitragem determina expressamente, a possibilidade de escolha da lei contratual pelas partes ${ }^{5}$.

\title{
4 PACTA SUNT SERVANDA
}

A idéia da máxima do pacta sunt servanda assegura que, o contrato é lei entre as partes e que, por isso, deverá sempre ser respeitado e cumpridas as obrigações nele constantes.

Para melhor entendermos o princípio do pacta sunt servanda vale citar o ensinamento de Anísio José de Oliveira ${ }^{6}$.

\begin{abstract}
"Realmente, uma vez observadas as exigências legais, querendo isto dizer, possuindo o contrato um teor válido, as partes não podem dele mais se depreender, tornando-se obrigatório sua observância. Há como que uma equiparação entre a lei e o contrato, no que concerne à sua força coercitiva. $\mathrm{E}$ efetivamente, refere S. Lopes, entre o contrato e lei observam-se certos pontos de perfeita correspondência, exceto na extensão de sua eficácia, pois, enquanto a lei é uma ordem geral, destinada a uma coletividade, o contrato tem efeitos limitados às próprias partes contratantes. Dessa equiparação do contrato à lei, nasceu o princípio: pacta sunt servanda".
\end{abstract}

Não há como pensar em contratos sem passar pela idéia do princípio do pacta sunt servanda e da autonomia da vontade.

\section{CONCEITO DE CONTRATO INTERNACIONAL}

Neste contexto temos os contratos internacionais do comércio que, apesar da enorme dificuldade de conceituação, podem ser tidos como contratos onde um ou mais ordenamentos jurídicos estão em confronto, ou nas palavras de Irineu Strenger ${ }^{7}$, o contrato seria internacional quando houvesse:

\footnotetext{
“A manifestação bi ou pluri lateral das partes, objetivando relações patrimoniais ou de serviços, cujos elementos sejam vinculantes de dois ou mais sistemas jurídicos extraterritoriais, pela força do domicílio,

${ }^{5}$ Lei $\mathrm{n}^{\circ} 9.307$, de 23 de setembro de 1996.

${ }^{6}$ OLIVEIRA, Anísio José de. A teoria da imprevisão nos contratos. $2^{\underline{a}}$ ed. São Paulo: Leud, 1991, p. 19.

${ }^{7}$ STRENGER, Irineu.Contratos internacionais do comércio. São Paulo: LTr, 1986, p. 65.
}

Revista Brasileira de Direito Internacional, Curitiba, v.2, n.2, jul./dez.2005 
nacionalidade, sede principal dos negócios, lugar do contrato, lugar de execução ou qualquer circunstância que exprima um liame indicativo de direito aplicável".

Portanto, um dos principais fatores que caracteriza um contrato como internacional, é a ligação entre dois ou mais ordenamentos jurídicos, pela presença de um elemento de conexão ${ }^{8}$.

É importante ressaltar que interna, mas principalmente internacionalmente, a autonomia da vontade em sentido amplo é bastante valorizada, o que gera a possibilidade das partes negociarem em sua avença as mais diversas modalidades de cláusulas, de acordo com suas necessidades e interesses.

Diante dessa liberdade contratual e da grande dificuldade na tentativa de uniformização das normas aplicáveis aos contratos internacionais, do risco acentuado a que estão expostos estes tipos de contratos - devido ao confronto de ordenamentos e economias mundiais - dentre outros fatores que geram a insegurança dos contratantes, surgem diversos mecanismos que possibilitam a adequação e a renegociação necessária no curso da execução do pacto, visto que, é eminente a possibilidade de ocorrência de adversidades que prejudiquem demasiado as prestações das partes.

\section{AS CLÁUSULAS DE REVISÃo}

A utilização de cláusulas contratuais que possibilitam a revisão e a adaptação dos contratos diante de uma circunstância nova e específica que onera a prestação (como a da imprevisão, a de hardship, a do rebus sic stantibus, dentre outras) para então desobrigar o devedor do cumprimento da obrigação onerosa e rever ou resolver pacto buscando seu re equilíbrio, é de grande valia no mundo dos negócios internacionais - onde as circunstâncias se alteram cotidianamente como uma forma de proteção do equilíbrio contratual e, portanto da própria validade, eficácia e continuidade dos contratos.

\footnotetext{
${ }^{8}$ ARAÚJO, Nádia de. Direito internacional privado: teoria e prática brasileira. 2 ed. Rio de Janeiro: Renovar, 2004. p. 318.
}

Revista Brasileira de Direito Internacional, Curitiba, v.2, n.2, jul./dez.2005 
Em um cenário comercial internacional que cada vez mais busca parcerias duradouras, preza pela continuidade dos contratos e assim pela manutenção de clientela e de bons negócios, as cláusulas que possibilitam a renegociação e a adaptação do contrato ao longo do tempo, mostram-se como um excelente instrumento de manutenção do contrato e dos negócios, quando a extinção contratual parece desvantajosa.

De uma forma mais concreta vale dizer que se não forem utilizadas nenhuma dessas cláusulas e alguma adversidade ocorrer ao longo do cumprimento do contrato, onerando excessivamente a realização de uma prestação, a única solução será a resolução do contrato, pois por mais onerosa que se torne a prestação, ainda assim será devida pela parte que provavelmente não conseguirá adimpli-la, culminando necessariamente no término da relação jurídica. Em contrapartida, ao utilizarmos as cláusulas de readaptação e revisão contratual, existe a possibilidade de descartar a prestação onerosa desobrigando a parte devedora e renegociando o contrato, obtendo-se novamente o equilíbrio e, dessa forma, a continuidade da relação.

É preciso ressaltar, conforme dito a cima, que a autonomia da vontade para a escolha da lei aplicável ao contrato sofre restrições em nosso ordenamento, diante disso, há que se pensar na possibilidade da lei escolhida ou imposta pelo legislador ao contrato, não recepcionar as cláusulas revisionistas eleitas pelas partes.

Nestes casos, a decisão pela validade ou não de tais cláusulas depende do juiz ou do árbitro que irá solucionar o litígio, diante disso, o que vem se observando repetidamente é que a autonomia da vontade em sentido amplo (para a escolha das cláusulas e da forma de contratar) é o princípio privilegiado pelos árbitros e juízes, que a despeito da não recepção da lei contratual às teorias revisionistas, têm decidido, em sua maioria, por aplicar e dar validade às cláusulas e instrumentos eleitos expressamente pelas partes em seus contratos.

Mas então, com essa tendência revisionista, estaremos deixando de lado o importante conceito trazido pelo pacta sunt servanda - que preceitua a manutenção e o cumprimento do contrato em seus exatos termos - em nome 
dos institutos que flexibilizam as obrigações e proporcionam a revisão contratual?

As cláusulas contratuais que possibilitam, diante de uma situação excepcional, a desoneração da obrigação do devedor de determinada prestação e a revisão dos termos contratuais, contrariam o princípio do pacta sunt servanda que determina que as obrigações contratuais são lei entre as partes e, portanto não podem ser descartadas?

É preciso analisar mais de perto algumas das principais cláusulas da teoria revisionista para que se possa chegar a uma conclusão quanto ao seu propósito e a sua contrariedade ou não ao pacta sunt servanda.

\section{O PRINCÍPIO REBUS SIC STANTIBUS}

Prosseguiremos nosso estudo com o instituto que fundamenta e embasa a maioria das cláusulas de revisão contratual, o princípio rebus sic stantibus.

O princípio rebus sic stantibus determina que o contrato e suas obrigações são válidos enquanto as circunstâncias permanecerem como estavam no momento de formação do contrato, ou seja, se algo alheio à vontade das partes modificar as circunstâncias e dificultar a realização de determinada obrigação, esta obrigação não será devida e o pacto poderá ser revisto, já que as circunstâncias que envolvem o acordo não são mais as mesmas e que a relação está desequilibrada.

Importante fazer a distinção entre a impossibilidade absoluta e a impossibilidade relativa. A primeira diz respeito às situações em que a prestação ou a execução do contrato como um todo se torna absolutamente impossível, podendo ser claramente observada nos casos de força maior. A segunda - que ocorre nos casos de imprevisão, rebus sic stantibus e hardship - é observada quando a execução ou a prestação não é em si impossível, mas traz grande dificuldade, ou encontra-se excessivamente onerada à parte. A teoria revisionista, como 
um todo, se baseia na idéia de impossibilidade relativa, daí a importância desta distinção.

\subsection{PRINCÍPIO OU CLÁUSULA?}

Uma questão peculiar é que o rebus sic stantibus deve ser pensado como princípio $^{9}$ e não como cláusula, já que, independentemente de estar escrito expressamente no contrato, deve orientar a interpretação contratual como um todo e poderá ser invocado livremente pelas partes no caso de surgimento de um litígio, sendo assim, por mais que não esteja previsto contratualmente e/ou que a lei do contrato não admita sua validade, poderão as partes invocá-lo, cabendo ao juiz ou ao árbitro decidir por sua aplicação, conforme as leis do foro do litígio e sua interpretação da noção de contrato.

Além disso, o princípio rebus sic stantibus mostra-se de grande importância, pois trouxe a idéia de equilíbrio contratual e de manutenção do equilíbrio existente no momento da contratação como condição de exigibilidade das obrigações, servindo de fundamento para o surgimento da maioria das cláusulas da teoria revisionista, dentre elas, a teoria da imprevisão e a cláusula de hardship, de vasta utilidade no âmbito das relações comerciais contratuais, principalmente nas internacionais.

\section{A TEORIA DA IMPREVISÃO}

A teoria da imprevisão não é somente uma adaptação do rebus sic stantibus, mas sim, uma derivação do antigo princípio, já que este foi a base que permitiu o surgimento da teoria.

Ambos os institutos, apesar de intimamente ligados e pertencentes à teoria revisionista, guardam diferenças essenciais, pois enquanto que, para caracterizar o rebus sic stantibus é necessário apenas que um fato desequilibre a relação contratual, ensejando assim a

${ }^{9}$ OLIVEIRA, Anísio José de. A teoria da imprevisão nos contratos. $2^{2}$ ed. São Paulo: Leud, 1991, p. 32-33.

Revista Brasileira de Direito Internacional, Curitiba, v.2, n.2, jul./dez.2005 
revisão do pacto e a desobrigação do devedor, para a teoria da imprevisão é necessário o elemento "imprevisão", além de outros requisitos como tempo, desequilíbrio e exterioridade, no que se diferenciam e se afastam.

\subsection{CONCEITO}

Segundo a teoria da imprevisão, as partes podem rever as disposições contratuais, ou ainda, solicitar judicialmente tal revisão com o intuito de re equilibrar a relação contratual. Essa possibilidade surge quando - da ocorrência de fatos novos ou situações imprevistas no momento da assinatura do contrato que venham a influir diretamente sobre ele - ocorre uma dificuldade ou onerosidade excessiva à prestação de uma das partes.

Importante afirmar que, se de um lado, é essencial a presença do elemento onerosidade excessiva, por outro, não é necessário o elemento vantagem excessiva para a outra parte. Além disso, a teoria da imprevisão pressupõe fatos alheios à vontade das partes, sendo, portanto, excludente de culpa.

\subsection{REQUISITOS}

Válido aqui ressaltar os quatro requisitos para a aplicação da teoria da imprevisão.

\subsubsection{Momento da Ocorrência}

Como primeiro requisito temos o fator tempo que determina que o fato que venha a agravar a prestação seja posterior à conclusão do contrato e anterior à sua execução completa.

Revista Brasileira de Direito Internacional, Curitiba, v.2, n.2, jul./dez.2005 


\subsubsection{Alteração das Circunstâncias}

Um segundo requisito é a necessidade de alteração das circunstâncias, pois quando o fato não incide sobre o contrato, ou incidindo não altera as circunstâncias, não há porque se falar na utilização da teoria.

\subsubsection{Onerosidade Excessiva}

Como terceiro requisito tem-se a onerosidade excessiva, já que além de incidir sobre o contrato e alterar suas circunstâncias é preciso que o fato cause dificuldade ou onerosidade ao cumprimento da prestação de uma das partes.

\subsubsection{Imprevisão}

Um dos pontos mais delicados quando se aplica a teoria da imprevisão é a verificação da ocorrência do fato imprevisto, visto que, sem tal fato não se poderá invocar a teoria e sua real imprevisibilidade mostra-se, no caso concreto, de difícil definição. Além disso, apenas algo que, de forma imprevisível, surgisse contra a vontade das partes, poderia ser aceito como suficiente para modificar o que outrora foi livremente convencionado por elas.

Para começar, é importante atentar que a imprevisibilidade não necessariamente recai sobre o fato, podendo recair apenas sobre suas conseqüências.

Vamos tentar então estabelecer algumas premissas que devem ser levadas em consideração na hora da análise da imprevisibilidade dos fatos ou de suas conseqüências, lembrando que a imprevisibilidade deve ser valorada no caso concreto sob pena de sempre considerarmos todos os fatos como previsíveis e assim, tornarmos impossível a utilização da teoria.

Revista Brasileira de Direito Internacional, Curitiba, v.2, n.2, jul./dez.2005 
A primeira afirmação que se deve fazer é que o fato imprevisível deve afetar a própria relação contratual, não bastando afetar a situação pessoal dos contratantes e que imprevisto para essa teoria é todo fato alheio à previsão das partes, que altera a ordem das coisas e desequilibra o contrato, vez que, agrava a prestação de uma delas, sendo obviamente posterior à conclusão deste.

Dentre as situações consideradas pela doutrina como imprevisíveis e que possibilitariam a revisão contratual, podemos citar os acontecimentos políticos ou econômicos do País, bem como fatores geográficos e sociológicos.

A imprevisão ocorre depois da formação do contrato e aleatoriamente à vontade das partes, sem a intervenção mesmo daquele que eventualmente se beneficiaria - não é necessário que ocorra um benefício para uma das partes, apenas o malefício para a outra - com o desequilíbrio.

Partindo disso, percebe-se que, se a parte pudesse prever a ocorrência do fato agravante de sua obrigação, certamente não seria aquela a sua manifestação de vontade, então, toda circunstância alheia ao contrato, e conseqüentemente alheia à vontade das partes, que venha a causar onerosidade excessiva à prestação de uma delas, será considerada imprevista.

Por óbvio que ninguém quer ter sua prestação excessivamente onerada então, se a parte pudesse prever a ocorrência do fato posterior a conclusão do contrato, que oneraria sua prestação, certamente não manifestaria sua vontade naqueles moldes, mas em outros que a protegeriam dessa onerosidade.

\subsubsection{Imprevisto para quem?}

Para concluirmos nossa idéia sobre o que é imprevisto, ou imprevisão, é necessário perguntar: imprevisto para quem? 
A imprevisibilidade deve ser considerada do ponto de vista de um profissional diligente, que mesmo observando todos os preceitos de cautela tem sua prestação onerada e/ou sua execução comprometida, por fatos que não estavam ao seu alcance no momento da celebração do contrato.

A imprevisão deve ser analisada a partir da parte onerada e da sua manifestação de vontade, não esquecendo, entretanto, de valorar em cada caso concreto a ocorrência do fato imprevisto quanto ao tempo (posterior à conclusão), à alteração das circunstâncias (se incide ou não no contrato) e à onerosidade excessiva (se gera ou não onerosidade), mas não quanto a sua imprevisibilidade, já que esta, seguindo essa linha de raciocínio, é óbvia.

Sendo assim, para a parte que tem a sua prestação onerada 0 fato sempre será imprevisto, ainda que previsível do ponto de vista de terceiros, vez que, obviamente a onerosidade não é algo desejado por ela.

\subsection{FUNÇÃO}

Diante do conceito e dos requisitos da teoria é preciso analisar também sua função. Seria injusto determinarmos a validade absoluta dos contratos, obrigando sua execução pelas partes, não importando à qual situação se submetesse. Sendo assim, a teoria da imprevisão tem a função de proteger os contratantes para que eventos novos, ocorridos no lapso de tempo entre a formação do contrato e o efetivo cumprimento da obrigação, não acarretem onerosidade excessiva ou enorme dificuldade na realização da prestação de um deles, disponibilizando nesses casos a revisão contratual, desobrigando a parte devedora.

Existe também a possibilidade de resolver o contrato com base na teoria da imprevisão, entretanto a opção de revisão vem sendo mais importante e mais utilizada, no cenário do comércio internacional, tida 
via de regra, como preferencial $^{10}$ à resolução, motivo pelo qual este estudo confere mais atenção à opção revisionista que à de resolução.

O contrato deve ser analisado do ponto de vista do próprio contrato e não de uma ou de outra parte especificamente. O que deve se objetivar é o seu equilíbrio como condição inclusive de sua validade, portanto, se algo gerar desequilíbrio, não há motivo para que o contrato não seja revisto e, dependendo do caso, a obrigação seja descartada.

Sendo assim, descartar a obrigação onerosa, para então rever o pacto e encontrar prestação mais adequada ao caso concreto, re equilibrando a relação contratual, é a função da teoria da imprevisão.

\subsection{APLICABILIDADE}

Diante de todo o exposto percebe-se que a aplicação da teoria da imprevisão sempre deve ser pensada com cautela. Não há dúvidas de que a invocação da teoria, a desobrigação e a revisão ensejada por ela podem ser de grande utilidade no mundo dos negócios, onde as circunstâncias se alteram cotidianamente, seja como uma forma de preservação da vontade das partes, seja como via de proteção de desmedidas onerosidades, como pelo equilíbrio e, portanto pela própria validade, eficácia e continuidade dos contratos.

Entretanto, por estar envolta por conceitos extremamente subjetivos e relativos, é dever do aplicador do direito pautar-se de extrema prudência ao decidir sobre sua aplicação, sob pena de utilizar essa poderosa arma em favor daqueles que buscam obter vantagens indevidas.

\footnotetext{
10 "Interessante é a observação de Gutierrez, no que se refere a esta polêmica, chegando a afirmar que é exagerado chegar imediatamente à rescisão, quando o que se deve buscar primeiramente é a modificação do contrato mediante revisão do mesmo." "Opinamos pela revisão como meio preferencial; no entanto o juiz poderá eleger a resolução se o dito meio preferencial for inadimissível ao caso." "E este nosso comedido e recatado parecer encontra ressonância em Ramon Badenes Gasset. Para o autor de El Riesco Imprevisible a cláusula rebus deve funcionar permitindo uma revisão nos contratos e uma dilatação de prazos." OLIVEIRA, Anísio José de. A teoria da imprevisão nos contratos. $2^{a}$ ed. São Paulo: Leud, 1991, p. 85-86.
}

Revista Brasileira de Direito Internacional, Curitiba, v.2, n.2, jul./dez.2005 


\section{A CLÁUSULA DE HARDSHIP}

O termo hardship poderia ser traduzido como "adversidade", "infortúnio" ou "endurecimento das condições" ${ }^{11}$, diante do qual o pacto deverá ser revisto e a obrigação onerosa descartada, sempre em busca do equilíbrio da relação jurídica.

A hardship é uma cláusula revisionista de adaptação não automática, pois pressupõe a renegociação do contrato, pelas partes ou por terceiros por elas indicados (juiz, árbitro, mediador, etc.). Geralmente é redigida de forma genérica, sem a necessidade de enumeração das circunstâncias que possibilitariam essa readaptação.

A cláusula de hardship está inserida dentro dos Princípios do UNIDROIT, em três artigos, 6.2.1 a 6.2.3, na secção $n . .92$, do capítulo $n . .06$, que tratam da observância do contrato, da definição e dos efeitos da cláusula, respectivamente.

O art. 6.2.1, dos Princípios do UNIDROIT diz respeito à observância do contrato, expondo, como regra geral, o seu caráter vinculativo onde:

\footnotetext{
“As partes estão adstritas ao cumprimento das suas obrigações, mesmo que a execução se tenha tornado mais onerosa, sem prejuízo do disposto nos artigos seguintes relativamente ao hardship." 12
}

Tem-se, portanto como regra geral o cumprimento do contrato em seus exatos termos.

Entretanto, o cumprimento de um contrato de longo prazo está sujeito a sofrer modificações, sendo raros os casos em que o adimplemento se dará de forma idêntica à pactuada e se essas alterações acarretarem uma dificuldade excessiva aos contratantes ou a um deles, gerando um desequilíbrio, estes poderão fazer uso, em caráter excepcional, da cláusula de hardship.

Os Princípios do UNIDROIT, em seu art. 6.2.2, define hardship, genericamente, como uma situação em que há a ocorrência de fatos que

11 PRADO, C. A. Maurício. Novas perspectivas do reconhecimento e aplicação do hardship na jurisprudência arbitral internacional. Revista Brasileira de Arbitragem, Curitiba, $n^{\circ} 2$, p. 34-35, abr/jun, 2004.

${ }^{12}$ Site: http://www.uff.br/cisgbrasil/principios.html- acesso em 05/06/2005.

Revista Brasileira de Direito Internacional, Curitiba, v.2, n.2, jul./dez.2005 
alteram fundamentalmente o equilíbrio do contrato, considerando estas modificações como reflexo da conjuntura social, econômica, política, tecnológica, e que possibilitam a revisão do pacto.

A alteração fundamental do equilíbrio do contrato é tratada de duas formas diferentes, mas correlatas, podendo ocorrer, por um lado, pelo aumento substancial dos custos do cumprimento da prestação de uma das partes, por outro lado, pela diminuição substancial, ou até pela perda total, do valor da contraprestação recebida. Não poderá, entretanto, ser qualquer aumento ou diminuição das prestações, deverá ser algo substancial, fundamental, que afete realmente o equilíbrio do contrato.

O objetivo da hardship seria então, a revisão e a renegociação contratual, ou não sendo possível, apenas em última hipótese, a resolução do contrato. Tal revisão se dá com base em dois critérios, o subjetivo fundado na idéia de lealdade entre as partes e naquilo que é apropriado diante das circunstâncias e o objetivo que visa restabelecer o equilíbrio que existia no momento de conclusão do contrato. Existe também um terceiro critério, mais utilizado em sede arbitral, que se refere à equidade das partes, devendo ser observado no momento de readaptação do contrato.

Como vimos, os Princípios do UNIDROIT ${ }^{13}$ que contêm as regras básicas sobre os contratos comerciais internacionais, bem como, a exposição do conceito e dos efeitos das cláusulas de hardship, são de grande utilidade para o esclarecimento e conseqüentemente para a correta aplicação dessa importante cláusula.

\subsection{REQUISITOS}

Como já foi dito, para que haja a renegociação do contrato e para que seja assim descartada a prestação onerada, a alteração das circunstâncias

13 O Instituto para a Unificação do Direito Privado - UNIDROIT - foi criado em 1926, pela Liga das Nações, com a finalidade de adaptar uma legislação de direito civil uniforme. $O$ UNIDROIT publicou em 1994 os "Princípios para os Contratos Comerciais Internacionais", que são utilizados como uma fonte para os tribunais, como base para novas leis e para auxiliar as partes que estão negociando um contrato, orientando e unificando as interpretações dos institutos contratuais. Site: http://www.unidroit.org - acesso em 05/06/2005.

Revista Brasileira de Direito Internacional, Curitiba, v.2, n.2, jul./dez.2005 
deve ser fundamental, devendo-se observar o caso concreto, ou seja, o contrato em si, bem como os fatos que o rodeiam para definir a gravidade da alteração das circunstâncias.

Mas para que se possa aplicar a cláusula de hardship, além de ser necessária a existência de um acontecimento que altere fundamentalmente 0 equilíbrio do contrato, quer por aumento do custo do cumprimento das obrigações, quer por diminuição do valor da contraprestação, onerando assim a prestação de uma das partes, é primordial a satisfação de mais quatro requisitos que abaixo serão descritos.

\subsubsection{Momento da Ocorrência}

O primeiro requisito é quanto ao tempo da ocorrência dos fatos que deram origem àquele desequilíbrio fundamental. É indiferente para a aplicação do hardship se os fatos ocorreram antes ou depois da celebração do contrato.

Os acontecimentos devem chegar ao conhecimento da parte lesada depois da conclusão do contrato, devendo este desconhecimento ser razoavelmente aceitável. Logo, leva-se em consideração o momento do conhecimento e não o da ocorrência do acontecimento.

\subsubsection{Imprevisto e Razoabilidade}

O segundo requisito é o fator imprevisto, pois, para se enquadrar uma situação como caracterizadora de hardship, as circunstâncias que dão causa à sua ocorrência não podem, razoavelmente, ser levadas em conta pela parte lesada até o momento da celebração do contrato, sendo um conceito mais brando do que o adotado pela teoria da imprevisão, determinado pela expressão "razoavelmente".

Sendo assim, se o acontecimento foi conhecido depois da conclusão, mas ocorreu antes da mesma, a hardship só será aplicada se as partes, razoavelmente, não tinham como tomá-lo em consideração. $O$ critério da 
razoabilidade baseia-se nos padrões de uma pessoa de conhecimento médio e refere-se expressamente à parte em desvantagem.

Entretanto, se os acontecimentos ocorreram após a celebração do pacto, estes fatos devem ser imprevisíveis - lembrando que mesmo assim, a imprevisibilidade é considerada de forma menos "exigente" do que na teoria da imprevisão.

\subsubsection{Inevitabilidade}

Um terceiro requisito para que o mecanismo da hardship funcione consiste naquilo que podemos designar, genericamente, por inevitabilidade. É preciso que os fatos que deram lugar àquela situação de desequilíbrio, escapem ao controle da parte que se encontra em desvantagem ou afetada, ou seja, os fatos devem estar fora de sua esfera de domínio causal sendo, portanto, inevitáveis.

É necessário que a parte afetada não pudesse ou devesse, em nome do princípio da boa-fé e também do dever de colaboração entre partes, evitar que os fatos tivessem aquelas reflexões sobre o contrato, ou mesmo, que tivessem ocorrido.

Estão excluídas, portanto, as situações em que os fatos em questão tenham a sua origem em um comportamento da parte.

\subsubsection{Assumir os Riscos}

O quarto e último requisito reside no fato de a parte assumir os riscos inerentes aos resultados da operação, pois não haverá hardship se a parte afetada tiver assumido o risco da alteração das circunstâncias. Neste caso, os riscos não precisam ter sido assumidos expressamente, uma vez que podem decorrer da própria natureza do contrato, como por exemplo, na situação típica de operações especulativas.

Portanto, a cláusula de hardship pode ser qualificada como um acontecimento que altera fundamentalmente o equilíbrio do contrato, quer pelo 
aumento da prestação, quer pela diminuição (até a perda total) da contraprestação, que só terá aplicabilidade se esse acontecimento tiver chegado ao conhecimento das partes após a celebração do contrato, possibilitando inclusive que os fatos tenham acontecido anteriormente à celebração, porém, devendo ser desconhecidos razoavelmente. Ainda, devemos observar que as partes não podem concorrer para o aparecimento do fato e tampouco podem ter assumido o risco inerente aos seus resultados.

\subsection{EFEITOS}

O art. 6.2.3, dos Princípios da UNIDROIT, enumera os efeitos do hardship, como sendo a renegociação, a possibilidade de suspensão da execução e o envio ao tribunal quando as partes não chegam a um consenso no que se refere à sua renegociação.

Preenchidos os requisitos para a ocorrência do hardship, a parte deve exigir a renegociação do contrato. A cláusula de hardship, por ser uma obrigação de meio, obriga as partes a renegociarem o contrato com propostas sólidas e razoáveis. É necessária ainda a indicação das razões do pedido de renegociação, que deve ser dirigida à outra parte sem demora injustificada em relação à tomada de conhecimento da situação de hardship. Não se prevê, expressamente qual a sanção para o desrespeito a uma destas exigências. Pode se afirmar que parte interessada não perde o seu direito à renegociação simplesmente porque não agiu a tempo, entretanto, esse atraso do pedido pode afetar a verificação da existência ou não da situação de hardship.

A imposição de fundamentação do pedido de renegociação pretende dar à outra parte as informações necessárias para que possa avaliar a sua razoabilidade, no entanto, não será necessária essa justificativa se os fatos que deram causa ao hardship forem notórios e/ou do conhecimento geral.

Segundo análise do artigo 6.2.3 dos Princípios da UNIDROIT, percebese que o pedido de renegociação não permite, por si só, à parte afetada, o direito de suspender a execução do contrato. Esta disposição tem em vista evitar a utilização abusiva do mecanismo, o qual deve manter a sua 
característica excepcional, todavia, há circunstâncias extraordinárias que justificam a suspensão da execução.

No caso das partes, mesmo fazendo uso do princípio da boa-fé e à luz do dever de colaboração, não conseguirem renegociar o contrato dentro de um prazo razoável, poderão ainda, recorrer aos tribunais judiciais ou arbitrais.

O tribunal chamado para solucionar o litígio possui o poder de escolher, verificados os requisitos de ocorrência da hardship, entre resolver o contrato, ou adaptá-lo com vistas a restaurar o seu equilíbrio, entretanto, o contrato só poderá ser resolvido se a sua adaptação não for razoável.

Quando for razoável a adaptação, o tribunal deve restabelecer o equilíbrio original e não impor às partes um novo contrato.

O tribunal deve procurar proceder com uma distribuição eqüitativa dos prejuízos entre as partes. Essa distribuição, entretanto, não terá que refletir a totalidade das perdas provocadas pela alteração das circunstâncias, pois, deve-se considerar a extensão do risco assumido por cada parte e os benefícios que ainda advenham do cumprimento do contrato.

10 AS DIFERENÇAS ENTRE REBUS SIC STANTIBUS, HARDSHIP E A TEORIA DA IMPREVISÃO

Após a análise dos principais institutos da teoria de revisão é importante traçarmos algumas importantes diferenças existentes entre eles.

É imprescindível mencionar que o princípio rebus sic stantibus foi a base de toda a teoria revisionista, do qual decorreram a teoria da imprevisão e a cláusula de hardship, portanto, muitas semelhanças são observadas entre os três instrumentos. Entretanto, existem diferenças importantes que precisam ser levadas em consideração.

Primeiramente, delineando um paralelo entre a cláusula de hardship e a teoria da imprevisão, percebemos que ambos se aproximam em muito e se afastam de forma tênue.

A primeira diferença entre estes instrumentos contratuais é que, com relação à cláusula de harship, observa-se um abrandamento no elemento 
imprevisto, abordado como aquilo que razoavelmente não se podia prever, enquanto que para a teoria da imprevisão, como o próprio nome denota, o elemento imprevisto é requisito severo para a aplicação.

A segunda diferença é quanto ao momento da ocorrência do evento imprevisível, se para a teoria da imprevisão o evento deve ocorrer no lapso de tempo entre a formação do contrato e a sua execução, para a cláusula de hardship admite-se que o fato tenha ocorrido antes mesmo da formação do contrato.

A terceira diferença a ser apresentada é com relação à natureza jurídica da obrigação, pois, a cláusula de hardship configura uma obrigação de meio, ou seja, a renegociação é a obrigação em si, enquanto que na teoria da imprevisão, apesar de ser enormemente preferível a renegociação, pode se passar à resolução do contrato.

Em um segundo momento é importante traçarmos um paralelo entre o princípio rebus sic stantibus e a cláusula de hardship. Verificamos aqui a mesma proximidade observada quanto à imprevisão, e também uma tênue linha de diferenciação.

Pode se afirmar, como primeira diferença, que enquanto o princípio nada fala sobre o elemento imprevisão, a cláusula o coloca como requisito de aplicação - ainda que considerado de forma mais branda do que na imprevisão.

A segunda diferença observada entre ambos os institutos, é as mesmas apontadas com relação ao confronto com a teoria da imprevisão, qual seja, quanto ao tempo de ocorrência do fato imprevisto que pode ser anterior a formação do contrato para a cláusula de hardship.

A terceira e última diferença observada é quanto à obrigatoriedade de renegociação clamada pela cláusula (natureza jurídica de obrigação de meio) e à rescisão ensejada pelo princípio.

Por fim, ao confrontarmos o princípio rebus sic stantibus com a teoria da imprevisão, percebemos que como os demais também se aproximam bastante, entretanto se afastam com relação a dois elementos cruciais, o primeiro é o elemento imprevisão que no princípio não é exigido, enquanto que, 
na cláusula é requisito severo para a aplicação. O segundo elemento é quanto à revisão que, para a teoria da imprevisão, é o meio preferencial e para 0 princípio rebus sic stantibus não é observada a abertura desta possibilidade.

\section{O FUNDAMENTO DA TEORIA DE REVISÃO}

Vale dizer que toda a teoria revisionista é fundada na idéia de equilíbrio ${ }^{14}$ das prestações e de equidade ${ }^{15}$, apresentando-se a equidade como uma idéia mais ampla que a do mero equilíbrio contratual por aproximar se da própria noção de justiça.

Tendo em vista que, a base do negócio jurídico repousa na idéia de equivalência das prestações, de tal forma que, se não houver equivalência não há sequer bilateralidade no ato negocial, a validade do contrato se vincula a esta condição e desaparecendo a base do negócio - equivalência desaparece também a correspondência do contrato à vontade das partes, tornando-se imperiosa a revisão para o restabelecimento da condição originalmente equilibrada.

Importante ressaltar que, a idéia de condição originalmente equilibrada, afasta a aplicação das cláusulas revisionistas aos contratos leoninos, já que, nestes o equilíbrio original jamais existiu.

Conforme dito acima, o fundamento das teorias repousa na idéia de equilíbrio e de eqüidade, o que nos leva a uma noção um pouco além da do equilíbrio meramente matemático, tomando-se em consideração, para essa definição, a condição pessoal das partes e a noção de "justiça" em si.

Sendo assim, por mais bem elaboradas que estejam as cláusulas de reajustes de preços e de multas e por mais quantificados que estejam os possíveis prejuízos de quebras contratuais, ainda haverá a possibilidade no caso concreto, de incidência das teorias revisionistas, pois o equilíbrio que as

\footnotetext{
${ }^{14}$ MELO, Jairo Silva. Contratos internacionais e cláusulas hardship. São Paulo: Aduaneiras, 1999, p. $114-117$.

15 "Trata-se a equidade de uma forma de, utilizando o dispositivo legal aplicável, adaptar a norma ao fato, impedindo que o rigor do direito objetivo se converta em atentado ao próprio direito." PEREIRA, Caio Mário da Silva. Instituições de direito civil. 10ª ed. São Paulo: Forense, 1987, p. 56.
}

Revista Brasileira de Direito Internacional, Curitiba, v.2, n.2, jul./dez.2005 
fundamenta não é meramente financeiro - caminhando lado a lado à noção de equidade - e dificilmente poderá ser calculado levando apenas em conta o critério matemático.

Entretanto, esforços no sentido de elaborar cláusulas completas em si trazem maior segurança às partes, mas não eliminam a possibilidade de ocorrência de fatos e situações além das previstas, que levariam a incidência da teoria revisionista, cabendo então ao juiz ou ao árbitro a função de restabelecer o equilíbrio contratual, atentando para tanto, ao equilíbrio matemático e à noção de eqüidade, de "justiça".

\section{A COMPLEMENTARIDADE}

Após uma análise mais detalhada percebe-se que a teoria, traduzida nas cláusulas contratuais acima estudadas, visa a equilibrar o pacto, por entender que não há contrato se não houver equilíbrio, sendo assim, se alguma circunstância específica onerar a prestação de uma das partes, desequilibrando a relação contratual, tal prestação deve ser descartada e o pacto deve ser revisto, como condição de sua validade.

A desobrigação do devedor quanto a uma prestação onerosa faz voltar o equilíbrio contratual, em sendo o equilíbrio uma condição de validade, a revisão apenas possibilita a continuidade dos contratos.

Em uma primeira análise poder-se-ia dizer, precipitadamente, que 0 princípio do pacta sunt servanda e as cláusulas revisionistas se contrariam e são sim opostos - segundo uma visão mais tradicionalista - ou ainda que, apesar de existir contradição essa oposição seria necessária para proteger as partes de situações extremas ou abusivas, entretanto, ao que parece, apesar da aparente contradição e a despeito da necessariedade dessa contraposição, os institutos são em verdade complementares, diversos entre si, mas não conflitantes ou contrários.

O princípio do pacta sunt servanda surge com o intuito de preservar os acordos e sua validade, bem como as cláusulas revisionistas, que buscam o equilíbrio contratual diante de uma circunstância que o desequilibra, para que 
os pactos continuem a existir e a produzir seus efeitos, sendo assim, são complementares na tentativa de proteção dos contratos e da vontade manifestada, um garantindo sua validade inicial e as outras assegurando a continuidade da relação contratual.

Portanto, não há confronto entre a teoria revisionista e o pacta sunt servanda, pois apesar da teoria revisionista desobrigar o devedor de sua prestação e o pacta sunt servanda determinar que a obrigação contratual é lei entre as partes, ambos fazem essa determinação com o mesmo objetivo que é a manutenção do pacto.

Apesar de serem institutos diferentes, se complementam e não se confrontam, pois buscam o mesmo objetivo final de forma e em momentos diferentes, fazendo parte de um mesmo todo na idéia de equilíbrio, validade e manutenção contratual.

Analisando que pacta sunt servanda significa que o pacto deve valer e rebus sic stantibus significa no mesmo estado de coisas, se as circunstâncias continuarem as mesmas do momento de conclusão do contrato ele deve prevalecer, entretanto se algo ocorrer e alterar fundamentalmente seu equilíbrio e seu propósito, ele deverá ser revisto e a obrigação onerosa descartada, para que se re estabeleça o equilíbrio e assim seja possível a sua manutenção.

Os institutos convivem em harmonia porque dependem um do outro para existirem e serem eficazes, neste sentido vejamos o que pondera Anísio José de Oliveira ${ }^{16}$ :

"Julgamos como J. M. Othon Sidou, ser o pacta sunt servanda letra morta sem a condição da rebus sic stantibus."

Conclui-se, por fim, que a aplicação crescente e tão importante dos institutos revisionistas não é uma forma de se deixar de lado a idéia de pacta sunt servanda, pois ambas fazem parte de um mesmo todo de preservação contratual e preservação da vontade que se complementam, uma não sendo excludente da outra, podendo e devendo participar inclusive da mesma sentença frasal, qual seja: Pacta sunt servanda se rebus sic stantibus.

\footnotetext{
${ }^{16}$ OLIVEIRA, Anísio José de. A teoria da imprevisão nos contratos. $2^{\underline{a}}$ ed. São Paulo: Leud, $1991, \underline{\text { p. } 155}$.
}

Revista Brasileira de Direito Internacional, Curitiba, v.2, n.2, jul./dez.2005 


\section{CONCLUSÃO}

Apesar do cuidado que deve ser tomado na aplicação dos institutos de revisão contratual, por serem bastante subjetivos e por seu caráter de aplicação excepcional, eles são de suma importância no cenário da contratação internacional e refletem uma tendência revisionista e mantenedora dos contratos cada vez mais relevante e crescente.

O princípio do pacta sunt servanda é também de grande relevância nas contratações, mas não pode ser analisado em separado da idéia trazida pelo princípio rebus sic stantibus.

Da mesma forma, não há como se falar em manutenção do estado de coisas existentes no momento da contratação e preservação do equilíbrio contratual, sem se considerar primeiramente a existência de um pacto, sua validade e obrigatoriedade, pois, se não tomarmos o pacta sunt servanda como regra base, não será possível, definir ou invocar, as teorias de revisão com vistas a equilibrar um contrato que jamais teve validade ou obrigatoriedade.

Diante disso diz se que, a despeito de serem institutos diferentes, estão e devem estar intimamente conectados, não existindo contrariedade ou oposição, mas complementaridade, ambos integrando um único, e por isso mais completo, conceito de manutenção contratual.

\section{REFERÊNCIAS}

ARAÚJO, Nádia de. Direito internacional privado: teoria e prática brasileira. 2 ed. Rio de Janeiro: Renovar, 2004.

GARCEZ, José Maria Rossani. Contratos internacionais comerciais: planejamento, negociação, solução de conflitos, cláusulas especiais, convenções internacionais. São Paulo: Saraiva, 1994.

GARCIA, Izer Hanna. Revisão de contratos no Novo Código Civil. Rio de Janeiro: AIDE Editora, 2003.

GRANZIERA, Maria Luiza Machado. Contratos internacionais: negociação e renegociação. São Paulo: ícone, 1993.

Lei 9.307 de 23 de setembro de 1996. Lei brasileira de Arbitragem. 
MELO, Jairo Silva. Contratos internacionais e cláusulas hardship. São Paulo: Aduaneiras, 1999.

OLIVEIRA, Anísio José de. A teoria da imprevisão nos contratos. $2^{\underline{a}}$ ed. São Paulo: Leud, 1991.

PEREIRA, Caio Mário da Silva. Instituições de direito civil. 10ª ed. São Paulo: Forense, 1987.

PRADO, C. A. Maurício. Novas perspectivas do reconhecimento e aplicação do hardship na jurisprudência arbitral internacional. Revista Brasileira de Arbitragem, Curitiba, $\mathrm{n}^{\circ} 2$, p. 32-60, abr/jun, 2004.

SIDOU, J. M. Othon. A revisão judicial dos contratos e outras figuras jurídicas. $2^{\underline{a}}$ ed. Rio de Janeiro: Forense, 1984.

STRENGER, Irineu. Contratos internacionais do comércio. São Paulo: LTr, 1986.

KLANG, Márcio. A teoria da imprevisão e a revisão dos contratos. $2^{a}$ ed. rev. e ampl. São Paulo: Editora Revista dos Tribunais, 1991.

http://www.unidroit.org - acesso em 05/06/2005.

http://www.uff.br/cisgbrasil/principios.html - acesso em 05/06/2005.

Revista Brasileira de Direito Internacional, Curitiba, v.2, n.2, jul./dez.2005 